\title{
Fitting a Poisson Regression Model to Reported Deaths from HIVIAIDS in Nigeria
}

\author{
Adenomon Monday Osagie ${ }^{1, *}$, Adenomon Clara Adebukola ${ }^{2}$ \\ ${ }^{1}$ Department of Mathematical Sciences, Nasarawa State University, Keffi, Nigeria \\ ${ }^{2}$ Department of Administration, The Federal Medical Centre, Bida, Nigeria
}

Email address:

admonsagie@gmail.com (Adenomon M. O.)

${ }^{*}$ Corresponding author

\section{To cite this article:}

Adenomon Monday Osagie, Adenomon Clara Adebukola. Fitting a Poisson Regression Model to Reported Deaths from HIV/AIDS in Nigeria. International Journal of Statistical Distributions and Applications. Vol. 3, No. 3, 2017, pp. 56-60. doi: $10.11648 /$ j.ijsd.20170303.15

Received: March 14, 2017; Accepted: May 2, 2017; Published: October 31, 2017

\begin{abstract}
The Human Immunodeficiency Virus (HIV)/Acquired Immunodeficiency syndrome (AIDS) epidemic has become one of the greatest challenges to public health among adults in Sub-Saharan African. In Nigeria, HIV/AIDS epidemic remain one of the major causes of death in the general population, particularly among young adult. In this paper, we will use Poisson regression model to study the linear trend of annual deaths resulting from HIV/AIDS in Nigeria for the period of 1996 to 2004. The result from the Poisson regression revealed an increase in rate of death resulting from HIV/AIDS in Nigeria. Therefore, there should be increase in the level of awareness of HIV/AIDS and other precautionary measures should also be observed in other to reduce the menace.
\end{abstract}

Keywords: Fitting, Poisson Regression, Deaths, Human Immunodeficiency Virus (HIV), Acquired Immunodeficiency Syndrome (AIDS)

\section{Introduction}

Over the past decades, Human Immunodeficiency Virus (HIV) infection remains a serious global public health and development challenges in human history [1]. According to the World Health Organisation (WHO) and the United Nations joint program on AIDS (UNAIDS), about 25 million persons have died since 1981 , and 33 million are currently infected with HIV [1].

In Nigeria, a country with a population of about 140 million in 2006 is not spare from HIV/AID scourge [2]. As noted by [3], that Nigeria has the highest prevalence rate in west African sub-region and the third highest prevalence of any country in the world with five percent population prevalence rate, which about to over 3.6 million people.

Nigeria's epidemic is characterized by one of the most rapidly increase rates of new HIV/AIDS cases in West Africa. Adult HIV prevalence increase from 1.8 percent in 1991 to 5.8 percent in 2001 [4]. Several factors have contributed to the rapid spread of HIV in Nigeria. These include sexual networking practices such as polygamy, a high prevalence of untreated sexually transmitted infections (STIs), low condom use, poverty, low literacy, poor health status, low status of women, stigmatization, and denial of HIV infectious risk among vulnerable groups. Nigeria is a complex mixture of diverse ethnic groups, languages, cultures, religious and regional political groups, all of which are challenges for HIV prevention programs. The detail of such interest can be seen in works like [5-7].

As noted by [8] that the widespread and rising HIV/AIDS is a problem that could be affecting the growth of the Nigerian economy which, led to compounding poverty, low standard of living, low productivity, increased unemployment, morbidity and mortality rates and ultimately obstruct development efforts. [9] added that economic development and human health in Africa continues to decline as a result of the menace of infectious diseases (e.g. HIV/AIDS, ebola, typhoid fever and malaria).

In this work, our focus is to model the number of deaths related to HIV/AIDs in Nigeria with the application of Poisson regression model. 
The HIV/AIDs is one of the leading causes of adult mortality in Sub-Saharan Africa [10]. The epidemic has become one of the greatest challenges to public health among adults in sub-Saharan Africa. However in Nigeria, HIV/AIDs epidemic remains one of the major causes of deaths in the general population, particularly among young adult [11].

Table 1. 2010 Global Reports on estimates in 2009 for (Adult + Children).

\begin{tabular}{llll}
\hline & Nigeria & Sub-Saharan African & Global \\
\hline Estimated people living with HIV & $3,300,000$ & $22,500,000$ & $33,300,000$ \\
Estimated AIDS-Related Deaths & 220,000 & $1,300,000$ & $1,800,000$ \\
\hline
\end{tabular}

Source: [12]

The table 1 above revealed a high figure for estimated death from AIDS. Due to this alarming statistics, the National HIV/AIDS strategic framework (2005-2009) was developed by NACA with contributing effort of nongovernmental organizations such as WHO, UNAIDS etc to fight against HIV/AIDS in Nigeria [13].

\section{Literature Review}

The work of [14] applied the UNAIDS Estimation and Projection Package (EPP) to HIV/AIDS epidemic in the north central zone of Nigeria. Their result revealed that about 378,870 people are expected to die due to the epidemic in the year 2010. The result further added that the mortality rate is still on the rise. In [15] used the EPP to model the prevalence of HIV/AIDS epidemic in four West African countries (Nigeria, Ghana, Cote d'Ivoire and Senegal). Their result revealed that the estimated prevalence remained higher for Cote d'Ivoire than the rest of the countries, while for the default model, Nigeria had the highest prevalence estimate.

Also [16] examined NOUN's basic structures that position the university to respond to the HIV/AIDS epidemic and assessed HIV/AIDS strategies and policy framework the university has put in place. The results showed that NOUN has identified the impact the epidemic has on university, although it has yet to institutionalized an HIV/AIDS policy.

In another work of [17] developed statistical models to adequately describe the spatial distribution of the Nigerian HIV/AIDS epidemic and its associated ecological risk factors. He also developed models that could reconstruct the HIV incidence curve and provided short term projection for AID incidence in Nigeria. The results revealed that Nigeria HIV/AIDS pandemic is made up of multiple epidemics spatially located in different parts of the country with most of them having the potential of being sustained into the future given information on some risk factors.

The work of [18] proposed mathematical models for understanding the epidemiology of HIV/AIDS. Evidence from numericalization, the models revealed that AIDS disease progressively increased with year (time) and concluded that if this current trend is unchecked, a catastrophic AIDS epidemic (Pandemic) will occur in the near future.

In a similar work, [19] examined the dynamics of HIV/AIDS with treatment and vertical transmission. They proposed a non linear deterministic mathematical model and the result revealed that using treatment measures and control of the rate of vertical transmission have the effect of reducing the transmission of the disease significantly.

The work of [20] proposed a computational model for the control of HIV/AIDS disease in a heterosexual population. Their result from numerical experiments revealed that the control of HIV/AIDS in heterosexual population dependent on the following factors: rate of taking the preventive measure, proportion of the infected taking the preventive measures etc.

In addition, [8] investigated the impact of HIV/AIDS on economic growth and development in Nigeria using primary and time series data. The study also looked at the effect of the epidemic on saving and standard of living. The findings revealed that HIV/AIDS prevalence is widely spreading and rapidly rising and has a negative impact on real GDP growth in Nigeria.

The work of [21] examined how four major Nigerian Newspapers (The Guardian, Punch, Daily Trust \& New Nigerian) communicate issues regarding HIV/AIDS in Nigeria. The study concluded that activity model of HIV/AIDS communication dominated the four Nigerian mainstream newspaper studied.

The work of [22] modeled HIV/AID variable in Nigeria (a case study of Bishop Shamahan Missionary Hospital Nsukka) using contingency analysis. Most of the variables considered in the study revealed independence.

The work of [23] developed and analyzed a mathematical model of HIV/TB co-infection. The model was a first order ordinary equation. Their result revealed that the endemic equilibrium state was stable.

Lastly, [9] reviewed the role of computational and mathematical models play in proferring solution to infectious diseases (HIV/AIDS, ebola, typhoid fever and malaria). They concluded that knowledge of computational and mathematical modeling has improved the approach in managing and combating the transmission of these infectious diseases. And also it has helped in predicting risks of major outbreaks in Africa.

\section{Poisson Regression}

In statistics, Generalized Linear Model (GLM) are an extension of the linear modeling process that allow model to be fit to data that follow probability distributions other than the normal distribution [24]. Poisson regression model is a special case of a generalized linear model (GLM) with a log link - this is why the Poisson regression may also be called 
Log-Linear Model. Consequently, it is often presented as an example in the broader context of GLM theory [25]. Poisson regression is a form of a GLM where the response variable is model as having a Poisson distribution. The Poisson distribution is often used to model rare events [26].

Suppose the observed counts $n_{i}\left(n_{i} \geq 0\right)$ follow a Poisson distribution with parameter $\lambda$. Then from Poisson distribution properties, we have $E\left(n_{i}\right)=\lambda$ and $\operatorname{Var}\left(\mathrm{n}_{\mathrm{i}}\right)=\lambda$

We assume here that observed counts occur over a fixed interval, and because these counts are nonnegative, a Poisson regression model is defined in terms of log of expected counts $\left(\hat{m}_{i}\right)$ as: $\ell_{i}=X^{\prime} \beta$ where the $\mathbf{X}$ represents the explanatory variables [27].

In this work we will look at the simple case of a Poisson regression as $\log _{e}(Y)=\beta_{o}+\beta_{1} X_{1}$. In other words, the typical Poisson regression model expresses the log outcome rate as a linear function of a set of predictors.

The assumptions of Poisson regression model include:

a. Logarithm of the disease rate changes linearly with equal increment increases in the exposure variable.

b. Changes in the rate from combined effects of different exposures or risk factors are multiplicative. c. At each level of the covariates the number of cases has variance equal to the mean.

d. Observations are independent.

Poisson regression and fitting the Poisson distribution are discussed in [28]-[30].

\section{Data}

Data used for this work was extracted from Annual Abstract of Statistics, 2006 a publication of NBS. Annual data on reported deaths from notifiable disease (HIV/AIDS) for a period of 1996 to 2004 was collected. The response variable used is death related to HIV/AIDS and the predictor is the year coded from 0 to 8 inclusive.

\section{Data Analysis and Discussion of Results}

The data was analyzed using STATA 8 Statistical Software. The results for Poisson regression and Goodnessof-fit test after Poisson are presented below in table 2 below.

Table 2. STATA 8 Outputs on Poisson Regression Model.

\begin{tabular}{|c|c|c|c|c|}
\hline \multicolumn{5}{|c|}{ poisson rhiv $\mathbf{x}$} \\
\hline \multicolumn{5}{|c|}{ Iteration 0: $\log$ likelihood $=\mathbf{- 1 4 5 . 9 7 1 7 3}$} \\
\hline \multicolumn{5}{|c|}{ Iteration 1: $\log$ likelihood $=\mathbf{- 1 4 5 . 9 7 0 5 6}$} \\
\hline \multicolumn{5}{|c|}{ Iteration 2: $\log$ likelihood $=\mathbf{- 1 4 5 . 9 7 0 5 6}$} \\
\hline \multicolumn{5}{|c|}{ Poisson regression Number of obs $=9$} \\
\hline \multicolumn{5}{|c|}{ LR $\operatorname{chi} 2(1)=645.40$} \\
\hline \multicolumn{5}{|c|}{ Prob $>$ chi $2=0.0000$} \\
\hline \multicolumn{5}{|c|}{ Log likelihood $=-145.97056$ Pseudo $R 2=0.6885$} \\
\hline rhiv & Coef. & Std. Err. & $\mathbf{Z} \mathbf{P}>\mathbf{Z}$ & [95\% Conf. Interval] \\
\hline $\mathrm{x}$ & .2487394 & .0103862 & 23.950 .000 & .2283829 .2690959 \\
\hline cons & 4.08387 & .0622081 & 65.650 .000 & 3.9619444 .205795 \\
\hline
\end{tabular}

poisgof

Goodness-of-fit chi $2=231.2019$

Prob $>\operatorname{chi} 2(7)=0.0000$

poisgof, pearson

Goodness-of-fit chi2 $=207.1273$

Prob $>\operatorname{chi} 2(7)=0.0000$

The fitted Poisson model is given as $\log _{\mathrm{e}}$ (rhiv) $=4.08387$ $+.2487394 \mathrm{X}$ and the positive value of $\beta_{1}=.2487394$ indicates an increase in the death due to HIV/AIDS annually in Nigeria, this result is similar to the result reported in [7] and [14]. While The Goodness-of-fit test after Poisson indicates a lack of fit of the model.

\section{Conclusion and Recommendations}

This work examines the trend in the death related to HIV/AIDS in Nigeria from 1996 to 2004 using the Poisson regression. The fitted Poisson regression model indicates an increase in the death due to HIV/AIDS annually in Nigeria which agrees with the result of [7] and [14].

Therefore, there should be increase in the level of awareness of HIV/AIDS. Government and NGO's should institutionalize best practices in care and support for people living with HIV/AIDS and also ensuring the availability of retroviral drugs for infected people. Other precautionary measures such as blood screening before transfusion, total abstinence from pre-marital sex etc should be observed in order to reduce the HIV/AIDS epidemic in Nigeria.

\section{References}

[1] Anude, C. (2008): Predictors and Prediction Modeling of Mortality Drop-Outs and Immuno-virologic outcomes among HIV-1 Infected Adults Receiving Highly Active Antiretroviral Therapy in Nigeria. A PhD Dissertation Proposal, John Hopkins University.

[2] National Population Commission (NPC) (2007): National and State Population Projections, 2006 Population Census Analysis, Abuja. 
[3] UNAIDS/WHO (2004): Epidemiological Fact Sheet on HIV/AIDS and Sexually Transmitted Infection Update. Working Group on Global HIV/AIDS and STI Surveilance.

[4] USAIDS (2002). A USAIDS Brief on HIV/AIDS in Nigeria. TvT Associates under The Synergy Project. July, 2002. www.usaid.gov/pop_health/aids/ or www.synergyaids.com. Retrieved on 23/09/2011.

[5] Akpa, O. M and Oyejola, B. A. (2006). Statistical Modelling of HIV/AIDS Epidemics: Nigeria's Most Needful Statistical Support for Meeting the MDGS in HIV/AIDS Intervention Initiative. In 2006 Conference Proceedings of the Nigerian Statistical Association. $13^{\text {th }}-15^{\text {th }}$ September 2006, Kano State: 143-149

[6] Adeyemi, R. A. (2006). Mathematical Modelling of the Effect of Public Health Campaign Against the Spread of HIV/AIDS Epidemics.. In 2006 Conference Proceedings of the Nigerian Statistical Association. $13^{\text {th }}-15^{\text {th }}$ September 2006, Kano State: 161-167.

[7] Dansu, B. M.; Dawodu, G. A. and Vincent, O. R. (2006). Statistical Contributions towards Combating HIV/AIDS as a way to Achieving the Millennium Development Goals (MDG).. In 2006 Conference Proceedings of the Nigerian Statistical Association. $13^{\text {th }}-15^{\text {th }}$ September 2006, Kano State: $175-182$

[8] Maijama'a, D. \& Mohammed, B. K.(2013): Impact of HIV/AIDS on Economic Growth and Development in Nigeria. Intl J. Basic \& Applied Science, 01(04): 763-772.

[9] Olugbenga, O. O.; Denye, N. O.; Adewole, A. \& Segun, A. F. (2016): Computational and Mathematical Modelling: Application to Infectious Disease Control in Africa. Asian J. Scientific Research, 9(3): 88-105.

[10] Timieus, I. M. and Jasseh, M. (2004). Adult Mortality in SubSaharan Africa: Evidence from Demographic and Health Surveys. Demography 41(4): 757-772.

[11] Akpa, O. M and Oyejola, B. A. (2009). Analysis of Trends and Projections of the Emergence, Impact and Epidemiology of HIV/AIDS in Nigeria: A paper presented at the $33^{\text {rd }}$ Annual Conference of the Nigerian Statistical Association, $12^{\text {th }}-14^{\text {th }}$ August, 2009. Zamfara State.

[12] Global Report (2010). Annex $1 \mathrm{HIV}$ and AIDS Estimates and Data 2009 and 2001: 176-207. http://www.usaids.org/en/Dataanalysis/Epidemiology. retrieved on 23/09/2011.

[13] Nasidi, A and Tekena, O. H. (2004). The Epidemiology of HIV/AIDS in Nigeria. AIDS in Nigeria: Harvard Centre for Population and Development Studies, 2004. 17-36.

[14] Akpa, O. M. \& Oyejola, B. A.(2007a): Statistical Modelling of HIV/AIDS Epidemic in the North Central Zone of Nigeria. Internet Journal of Infection Diseases, 6(2): 1-7.

[15] Akpa, O. M. \& Oyejola, B. A. (2007b): Modelling of HIV/AIDS Epidemics in West Africa: Results for UNAIDS Modelling Approach from Selected Countries. Res. J. Applied Sci, 2(11): 1148-115.

[16] Ambe-Uva, T. N. (2007): Combating HIV/AIDS Epidemic in Nigeria: Responses from National Open University of Nigeria (NOUN). IRRODL, 8(3): 1-21.

[17] Eze, J. I. (2009): Modeling HIV/AIDS Epidemic in Nigeria. A $\mathrm{PhD}$ Dissertation, University of Glasgow.
[18] Okereke, O. C. \& Bassey, E. J.(2010): On Application of Mathematical Modeling in the Spread in the HIV/AIDS Epidemic. Adv. In Nat. Appl. Sci. 4(3): 262-280.

[19] Waziri, A. S.; Massawe, E. S. \& Makinde, O. D. (2012): Mathematical Modeling of HIV/AIDS Dynamics with Treatment and Vertical Transmission. Applied Mathematics, 2(3): 77-89.

[20] Bulus, L. D; Wajiga, G. M. \& Zirra, P. B.(2013): Computational Model for Control of HIV/AIDS Disease in Heterosexual Population. The Intl J. Engineering \& Science, 2(7): 60-67

[21] Okidu, O. (2014): HIV/AIDS Communication in Four Nigerian Mainstream Newspapers. Pan. Afr. Med. J. 17 (Supp 1): 91-94.

[22] Asogwa, O. C. (2015): Modeling HIV AIDS Variables, A Case of Contingency Analysis. West Afr. J Industrial \& Academic Research, 14(1): 71-80.

[23] Bolarin, G. \& Omatola, I. U. (2016): A Mathematical Analysis of HIV/TB Co-Infection Model. Applied Mathematics, 6(4): 65-72.

[24] Mbata, U. A.; Olalude, G. A. and Okafor, R. O. (2009). On Generalized Linear Model: Poisson Regression Approach and Implementation: A paper presented at the $33^{\text {rd }}$ Annual Conference of the Nigerian Statistical Association, $12^{\text {th }}-14^{\text {th }}$ August, 2009. Zamfara State.

[25] Taylor, J. (2009). Poisson Regression: Introduction to Applied Statistics. Stanford University. http://www.stat.standford.edu/ jtaylo/courses/Stats191/notes/p oisson.pdf retrieved on 23/09/2011

[26] Larget, B. (2007). Poisson Regression. University of Wisconsin-Madison

http://www.stat.wisc.edu/courses/St572-

larget/spring2007/handouts24-2.pdf retrieved on 23/09/2011

[27] Lawal, H. B (2003). Categorical Data Analysis with SAS and SPSS Applications. London: Lawrence Erlbaum Associates, Publishers.

[28] Oyenuga, I. F; Ayoola, F. J. \& Shittu, O. I. (2016): Statistical Analysis of Pattern on Monthly Reported Road Accidents in Nigeria. Science Journal of Applied Mathematics \& Statistics, 4(4): 119-128.

[29] Adenomon, M. O. \& Evans, P. O.(2016): Cross Correlation Analysis on the Relationship Between Maximum Temperature and Relative Humidity in Bida, Niger State. International Journal of Agricultural Economics. 1(3): 62-66. doi: $10.11648 /$ j.ijae.20160103.12

[30] Adenomon, M. O.; Evans, P. O. \& Tela, M. N. (2017): Statistical Investigation on the Hydrolysis and Fermentation Processes of Cassava Peels in the Production of Bioethanol. International Journal of Statistics and Actuarial Science. 1(4): 92-100. doi: 10.11648/j.ijsas.20170104.11

[31] Berk, R. and MacDonald, J. (2007). Overdispersion and Poisson Regression. University of Pennsylvania. http://www.crim.upenn.edu/faculty/papers/berk/regression.pdf. retrieved on $23 / 09 / 2011$

[32] Oyejola, B. A and Adebayo, S. A. (2004). Basic Statistics for Biology and Agriculture Students. Nigeria: Olad Publishers. 
[33] Zar, J. H. (1999). Biostatistical Analysis. India: Dorling Kindersley Pvt. Ltd.

[34] Anderson C. J. (2011). Poisson Regression or Regression of
Counts (\& Rates). University of Illinois at UrbanaChampaign.

www.ed.uiuc.edu/courses/EdPsy490AT/lectures/4glm3-

ha.online.pdf. retrieved on 23/09/2011 